\title{
Tratamiento quirúrgico del secuestro pulmonar extralobar de diagnóstico prenatal
}

\section{Surgical treatment of extralobar pulmonary sequestration diagnosed prenatally}

\author{
A. Herranz-Barbero ${ }^{1}$, C. Gómez-Martínez de Lecea ${ }^{2}$, A. Tamura ${ }^{3}$, W. Torre Buxalleu ${ }^{3}$, \\ V. Alzina de Aquilar ${ }^{1}$
}

\section{SR. DIRECTOR:}

El secuestro pulmonar (SP) es una malformación congénita del trato respiratorio interior infrecuente. Representa entre el $0,15 \%$ y $6,4 \%$ de las malformaciones pulmonares congénitas ${ }^{1}$. Consiste en una masa de parénquima pulmonar no funcionante, no comunicada con el árbol traqueobronquial, y que recibe irrigación aberrante de la circulación sistémica, principalmente de la aorta descendente. Su patogénesis es desconocida. Las manifestaciones clínicas dependen del tipo, tamaño y localización de la lesión. Puede ser asintomático, o producir desde neumonías recurrentes hasta fallo cardíaco por hiperaflujo de la arteria aberrante ${ }^{2}$. Los avances médico-terapéuticos han ampliado el campo de abordaje de esta patología. La mejoría en las técnicas de imagen permiten, hoy en día, realizar un diagnóstico ecográfico prenatal ${ }^{3}$. Postnatalmente, la técnica de elección para caracterizar la lesión probablemente sea el angioTAC. Su tratamiento depende de la clínica y la edad del paciente y consiste en cirugía o embolización.
Mujer sana, de 33 años de edad, primigesta, en cuya ecografía prenatal de las 20 semanas de gestación se objetivó un SP en lóbulo inferior izquierdo (LII) en el feto. La ecografía-doppler mostró una lesión hiperecoica ocupante de espacio de $21 \times 15 \times 20 \mathrm{~mm}$ en el pulmón izquierdo con aporte vascular desde la aorta torácica descendente (Fig. 1A). Se realizaron controles ecográficos quincenales observando únicamente un hidramnios leve (ILA=30) y manteniéndose en todo momento un perfil hemodinámico fetal normal. Padres no consanguíneos. No antecedentes familiares de malformaciones congénitas. Parto vaginal instrumentado con espátulas a las 38 semanas +1 día de gestación. Apgar 9/10. Recién nacido de sexo femenino con peso $2.920 \mathrm{~g}$, longitud $49 \mathrm{~cm}$ y perímetro cefálico $33 \mathrm{~cm}$. El tercer día de vida se le realizó un angioTAC bajo sedación en el que se observó un aumento de densidad sin aire ni broncograma en su interior, en la región posteromedial del LII (Fig. 1B). Se nutría por una arteria pro-

An. Sist. Sanit. Navar. 2012; 35 (2): 309-312

1. Departamento de Pediatría. Clínica Universidad de Navarra. Pamplona.

2. Facultad de Medicina. Universidad de Navarra. Pamplona.

3. Departamento de Cirugía Torácica. Clínica Universidad de Navarra. Pamplona.

Recepción: 9 de diciembre de 2011

Aceptación provisional: 14 de febrero de 2012

Aceptación definitiva: 22 de febrero de 2012

\section{Correspondencia:}

Ana Herranz Barbero

Clínica Universidad de Navarra

Departamento de Pediatría

Avda. Pío XII, nº 36

31008 Pamplona (Navarra) España

E-mail: anaherranzbarbero@gmail.com 
cedente de la aorta torácica descendente, que nacía próxima al hiato diafragmático y tienía drenaje venoso mixto, $90-95 \%$ a vena ácigos y el resto a la vena lobar inferior izquierda. Confirmó el diagnóstico de SP extralobar en LII y descartó la existencia de otras malformaciones asociadas. En las sucesivas revisiones de puericultura la paciente mostró un adecuado desarrollo estaturo-ponderal y permanecía asintomática, únicamente presentó infecciones víricas de vías respiratorias superiores propias de su edad. Se realizaron angioTAC de control cada 6 meses que no mostraron modificaciones de la lesión. El equipo médico multidisciplinar, formado por neumopediatras, anestesistas y cirujanos torá-
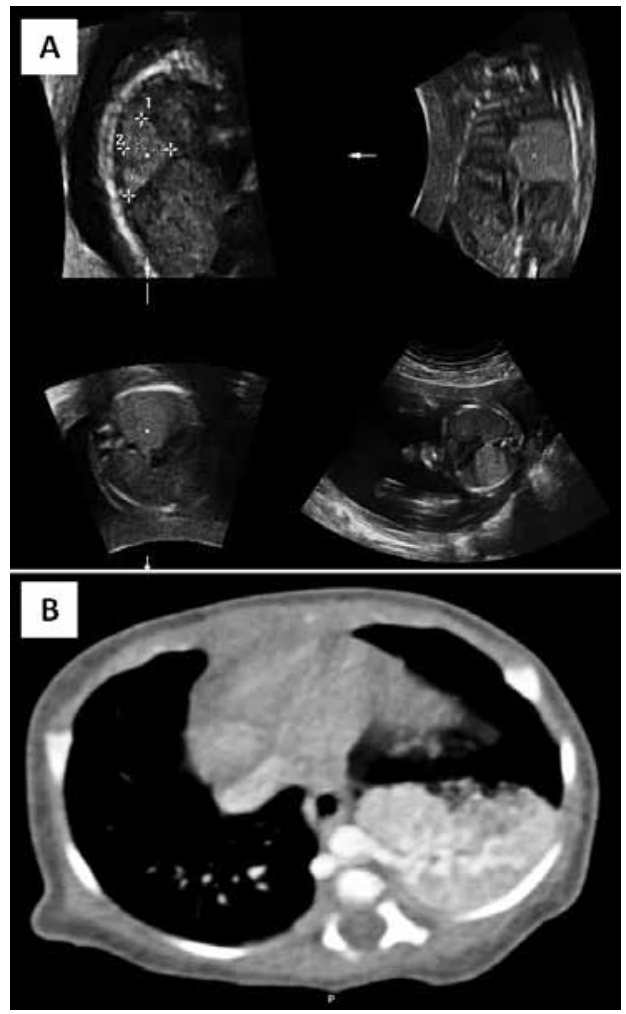

Figura 1. (A) Imágenes ecográficas prenatales. (B) TAC a los 3 días de vida. cicos, decidió que la cirugía era la mejor opción terapéutica para prevenir posibles complicaciones futuras. A los 15 meses de vida, momento en que la lesión tenía una dimensión de $34 \times 34 \times 27 \mathrm{~mm}$, se le realizó una toracotomía posterolateral izquierda preservando músculo serrato (Fig. 2). Se diseccionó y se ligó la arteria aberrante procedente de la aorta descendente, el ligamento triangular y el segmento pulmonar patológico, totalmente hepatizado. No se confirmó drenaje accesorio a vena ácigos. El postoperatorio transcurrió sin incidencias, retirando el drenaje torácico a las 48 horas. Tras 2 años de seguimiento no han surgido complicaciones.

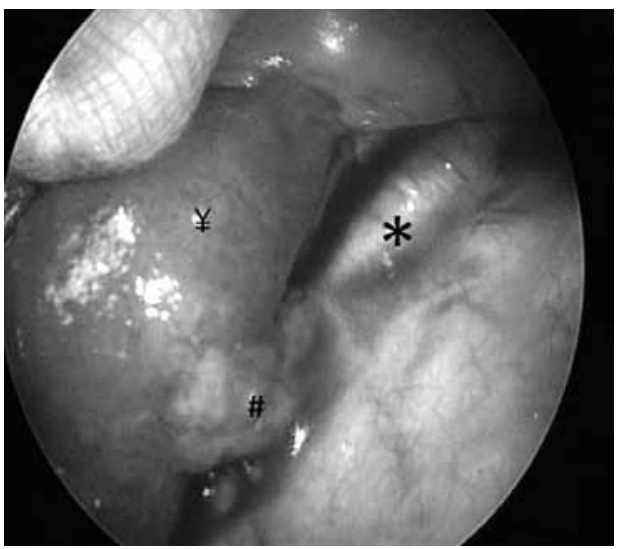

Figura 2. Foto intraoperatoria del secuestro pulmonar: aorta descendente $\left(^{*}\right)$, lecho vascular (\#), secuestro pulmonar ( $¥)$. 
El SP fue descrito en 1877 por Huber, pero el término lo acuñó Pryce en $1946^{4}$. Es una anomalía congénita poco frecuente del tracto respiratorio inferior, se trata de parénquima pulmonar no funcionante que recibe irrigación de la circulación sistémica y no comunica con el árbol traqueobronquial. Es más frecuente en varones. Se clasifican en dos grupos: intralobares, los más frecuentes (84\%), donde la lesión está rodeada por tejido pulmonar sano y suele diagnosticarse en niños o adultos jóvenes, y extralobares (15\%), que suelen detectarse en el periodo fetal o neonatal y tienen una pleura propia. La localización más frecuente es el LII (72\%). Se nutren de la circulación sistémica a través de arterias aberrantes que surgen desde la aorta torácica ( $76 \%$ ) o la abdominal, entre otras. El drenaje venoso más frecuente es a las venas pulmonares (91\%), aunque también pueden drenar a la vena ácigos o la semiácigos ${ }^{2,5}$. La paciente que se presenta tenía un SBP extralobar, situado en LII y con aporte sanguíneo desde la aorta torácica.

Las manifestaciones clínicas de SP intralobar suelen ser neumonías de repetición. Los extralobares pueden causar un distrés respiratorio en el recién nacido, o pasar desapercibidos hasta la edad adulta y confundirse con quiste pulmonar, cáncer de pulmón o tumores mediastínicos ${ }^{2,6}$.

Los avances en las técnicas ecográficas han permitido realizar el diagnóstico inicial en la etapa prenatal. Se visualiza como una masa homogénea hiperecoica; la ecogafía-doppler permite visualizar tanto la irrigación como el drenaje. Además, la ecografía permite realizar controles periódicos de la lesión y del desarrollo fetal. La confirmación postnatal debe realizarse mediante angioTAC, técnica que ha desplazado a la angiografía convencional ${ }^{3,7}$.

Las opciones terapéuticas son la cirugía convencional, la cirugía mediante vídeo-toracoscopia y la embolización. La técnica de elección sigue siendo un motivo de controversia. Algunos autores consideran que el tratamiento quirúrgico debe ser el de elección incluso en pacientes asintomáticos por dos motivos: prevenir las posibles complicaciones, infecciones respiratorias de repetición, hemoptisis, hemotórax o conversión a patología maligna; aumentar las posibilidades de resecar únicamente la lesión preservando el resto del parénquima pulmonar. Así mismo, no hay acuerdo sobre si la intervención debe realizarse intraútero o a los pocos meses de vida. Se han descrito casos en los que el SP extralobar produce hidrotórax a tensión que puede causar la muerte fetal, y por tanto, requiere tratamiento prenatal basado en shunts pleuroamnióticos con inyección de $1 \mathrm{ml}$ de alcohol puro, obteniendo resultados satisfactorios y evitando una intervención postnatal ${ }^{7}$. Por otro lado, la resección toracoscópica de SP en niños a partir de los tres meses de vida es una opción terapéutica factible y eficaz ${ }^{8,9}$. Estudios recientes apoyan la embolización como alternativa terapéutica del SP en niños mayores de tres meses de vida, consiguiendo una regresión total del SP si la oclusión de la irrigación aberrante es completa $^{10}$.

En el abordaje de los SP deben considerarse las diferentes opciones terapéuticas de forma completa e individualizada.

\section{BIBLIOGRAFÍA}

1. Carter R. Pulmonary sequestration. Ann Thorac Surg 1969; 7: 68-88.

2. Yong WeI, FAn Li. Pulmonary sequestration: a retrospective analysis of 2625 casesin China. Eur J Cardiothorac Surg 2011; 40: e39-e42.

3. YildiRIM G, GÜNGÖRdÜK K, Aslan H, CEYlan Y. Prenatal diagnosis of an extralobar pulmonary sequestration. Arch Gynecol Obstet 2008; 278: 181-186.

4. PRYce DM. Lower lobe accessory pulmonary artery with intralobar sequestration of lung: report of 7 cases. J Pathol 1946; 58: 457-467.

5. Corbett HJ, Humphrey GM. Pulmonary sequestration. Pediatr Respir Rev 2004; 5: 59-68.

6. Van Raemdonck D, De Boeck K, Devlieger H, Demedts M, Moerman P, Coosemans W et al. Pulmonary sequestration: a comparison between pediatric and adult patients. Eur J Cardiothorac Surg 2001; 19: 388-395.

7. Nicolini U, Cerri V, Groli C, Poblete A, Mauro F. A new approach to prenatal treatment of extralobar pulmonary sequestration. Prenat Diagn 2000; 20: 758-760. 
8. Jesch NK, Leonhardt J, Sumpelmann R, Gluer S, Nustede R, URE BM. Thoracoscopic resection of intra- and extralobar pulmonary sequestration in the first 3 months of life. J Pediatr Surg 2005; 40:1404-1406.

9. Rothenberg SS. Experience with thoracoscopic lobectomy in infants and children. J Pediatr Surg 2003; 38: 102-104.
10. Chien KJ, Huang TC, Lin CC, Lee CL, Hsieh KS, Weng KP. Early and Late Outcomes of Coil Embolization of Pulmonary Sequestration in Children. Circ J 2009; 73: 938-942. 